\title{
Fornix Transection: Discrimination Between Neuropeptide Effects on Attention and Memory
}

\author{
TJFERD B. VAN WIMERSMA GREIDANUS, GERDA CROISET AND GERARD A. SCHUILING ${ }^{1}$ \\ Rudolf Magnus Institute for Pharmacology, University of Utrecht \\ Vondellaan 6, Utrecht, The Netherlands
}

Received 20 February 1979

\begin{abstract}
VAN WIMERSMA GREIDANUS, T. B., G. CROISET AND G. A. SCHUILING. Fornix transection: Discrimination between neuropeptide effects on attention and memory. BRAIN RES. BULL. 4(4) 625-629, 1979._-Transection of the fornix and the stria terminalis completely blocks the inhibitory action of ACTH 4-10 on extinction of a conditioned avoidance response (CAR), whereas this effect of the vasopressin analogue des-glycinamide-lysine-vasopressin (DG-LVP) is not affected. These data indicate that the behavioral effect of DG-LVP may be localized to certain anatomical substrates, while ACTH 4-10 needs an intact limbic system as a functional substrate for its effect on avoidance behavior. This differential effect of fornicotomy may also be interpreted as a discrimination between the effects of these neuropeptides on attention or on memory consolidation. Additionally, transection of the fornix and the stria terminalis induces an increase in motor responsiveness to an electric footshock (F.FS) and a facilitation of acquisition of a C.AR.
\end{abstract}

Neuropeptides ACTH Vasopressin Fornix transection Avoidance behavior Responsiveness to EFS

IT HAS been shown that adrenocorticotropic hormone (ACTH) and its fragments such as ACTH 1-10 and ACTH 4-10 as well as melanocyte stimulating hormone (MSH) and related peptides of the ACTH family exert several behavioral effects [27], e.g., they affect extinction of active avoidance behavior [3, 24, 28, 32], improve passive avoidance behavior $[25,32]$ and seem to be involved in attention, motivation and/or retrieval processes $[16,21,26,30]$. These peptides have to be administered prior to behavioral testing [25,32]. Vasopressin, desglycinamide-lysine-8-vasopressin (DG-LVP) and related analogues, which are generally devoid of the antidiuretic, pressor and ACTH-releasing effects of vasopressin itself [29], also affect active and passive avoidance behavior. Vasopressin-like peptides act on behavior probably by an improvement of memory function at the levels of storage as well as of retrieval of information [31, 34, 36]. If consolidation effects are studied these peptides have to be administered during acquisition of a behavioral task [28,31]. Both categories of peptides act directly on the brain to produce these behavioral effects and several structures of the limbic system play a role in their actions. Extensive lesions in the dorsal hippocampal complex [35], in the septal region $[32,38]$ and in the amygdaloid nuclei [39] completely block the effects of vasopressin and ACTH and/or their fragments on extinction of a conditioned avoidance response (CAR), whereas the parafascicular nuclei appear to be essential for the behavioral effect of ACTH, but less important for that of vasopressin $[4,37]$. However, it has been proposed that these brain regions may not necessarily be the site(s) of behavioral action of these so-called neuropeptides but that the limbic system needs to be intact in order to allow them to display their inhibitory action on extinction of a CAR [35]. In order to test this hypothesis transections were made through the pre- and postcommissural fibers of the fornix and the stria terminalis immediately dorsal of the commissura anterior. Afterwards rats with these fornix transections were used to determine the inhibitory influence of the neuropeptides ACTH 4-10 and DG-LVP on extinction of a CAR. Additionally animals with fornix transections were compared with sham-operated animals in their responsiveness to electric footshock (EFS) and in their behavior in an open field.

\section{METHOD}

The transections were made in 60 male rats weighing 140-160 g (TNO, Zeist, The Netherlands) with a knife derived from that designed by Halász and Pupp [9]. The L-shaped knife, equipped with a horizontal blade with a length of $1 \mathrm{~mm}$, was lowered into the brain with its blade in the midline, to a depth of $6.5 \mathrm{~mm}$. Once the knife was properly located, it was rotated for $360^{\circ}$ causing a circular cut. In the sham-operated animals $(n=60)$ the knife was lowered to a depth of $4 \mathrm{~mm}$ and not rotated.

When the animals had returned to their pre-operative body-weight, usually 6-7 days after operation, they were subjected to conditioned avoidance training in a pole jumping apparatus $[24,33]$. In brief, the rats were trained to jump onto a pole in order to avoid a scrambled EFS. The light of a bulb placed on top of the box was used as conditioning stimulus. Acquisition sessions of 10 trials/day with a mean intertrial interval of $60 \mathrm{sec}$ were run on consecutive days until the criterion of $7.5 \mathrm{CAR}$ 's/session was reached as mean per-

'Laboratory of Experimental Endocrinology, University of Groningen, The Netherlands. 


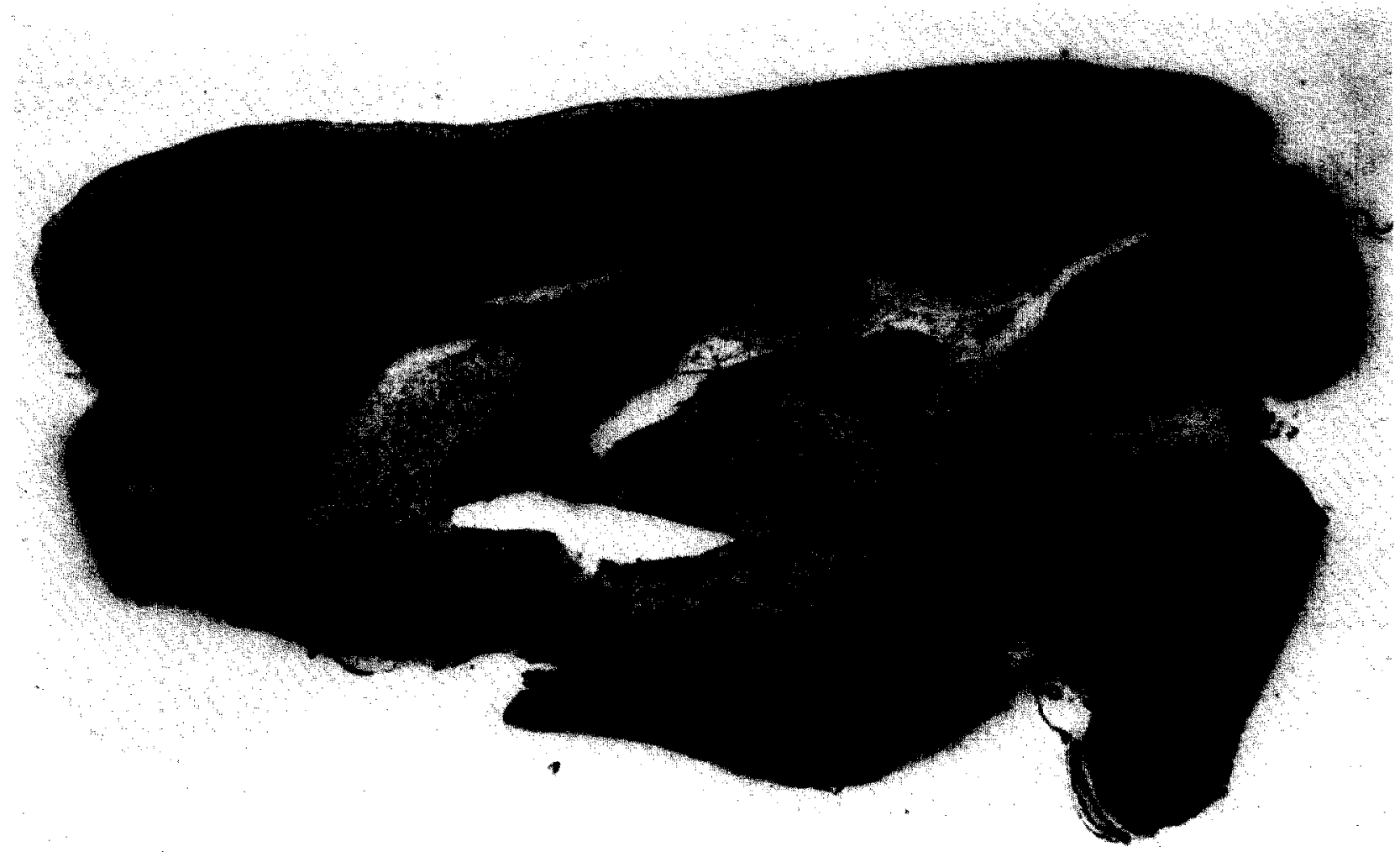

FIG. 1. Section of rat brain showing transection of the fornix (FO).

formance of both transected and sham-operated animals. After acquisition, extinction trials (10 trials/day) were performed during which no EFS was applied.

DG-LVP was injected subcutaneously (SC) immediately after the last acquisition session and extinction was then observed for 3 consecutive days. ACTH 4-10 was administered SC $1 \mathrm{hr}$ prior to each of the extinction sessions on 2 consecutive days. One dose level, $3 \mu \mathrm{g} / \mathrm{rat}$, of each peptide was used in sham-operated animals, whereas rats with fornix transections received injections of $3 \mu \mathrm{g}$ or $9 \mu \mathrm{g}$ of either ACTH $4-10$ or of DG-LVP. Saline $(0.5 \mathrm{ml})$ was used as a placebo. Animals were randomly allocated to different treatment groups.

Exploratory behavior of the animals was studied during 3 min sessions held on each of 3 consecutive days in a circular open field [23]. The behavioral parameters used during the sessions were ambulation (frequency of crossings of lines drawn on the floor of the open field), rearing, grooming and defecation. Furthermore the responsiveness of the rats to EFS was determined by scoring their percentages of jerk/run/jump reactions, flinches and no responses to various shock levels ranging from $0.31 \mathrm{~mA}$ to $0.187 \mathrm{~mA}[6,7]$. Ten different shock levels were used and each shock level was presented twice. The 20 EFS's were presented in a randomly fixed order. The duration of each EFS presentation was $1 \mathrm{sec}$ and the interval between presentations was $20 \mathrm{sec}$.

\section{RESULTS}

Rats with fornicotomy displayed a significantly higher amount of intense motor responses to EFS than did controls as was shown by the lower percentages of no responses and flinches and the higher percentages of jerk/run/jump reactions in this group of animals than in the sham-operated controls (Table 1). Moreover in the transected group the intense motor responses consisted of jerks as well as runs and jumps whereas in the sham-operated rat jerks were the only responses in this category. Furthermore, the difference in motor responsiveness to EFS between the two groups of animals was not associated with a difference in the frequency of vocalization during the presentation of the EFS.

The open field behavior of fornix transected rats differed only slightly from that of controls. Rearing, grooming and defecation were no different and ambulation was also similar in both groups during the first two days of observation. On the third day, the transected animals had a significantly $(p<0.05)$ higher level of ambulation but only a trend to higher rearing frequencies $(0.05<p<0.10)$ : grooming and defecation remained unaffected.

Sham-operated animals generally took one day more to reach the acquisition criterion on the pole jump avoidance training than did rats bearing fornix transection ( 5 vs 6 days) (see Tables 2 and 3).

DG-LVP has a long lasting inhibitory action on extinction of the CAR not only in sham-operated animals but also in rats with fornix transections. A single injection of the peptide immediately after the last acquisition session resulted in a dose dependent, long lasting inhibition of extinction of the avoidance response, as compared with saline treated animals (Table 2). In contrast the inhibitory action of ACTH 4-10 on 
TABLE 1

RESPONSIVENESS OF RATS WITH FORNIX TRANSECTIONS AND OF SHAM-OPERATED RATS TO EFS. RFSULTS ARF EXPRESSED AS PERCENTAGES (MEAN \pm SEM) OF CATEGORIES OF MOTOR RESPONSES AND AS FREQUENCY OF VOCALIZATION DURING A SINGLE SESSION OF 20 EFS PRESENTATIONS.

\begin{tabular}{lcccc}
\hline & No Response & Flinch & Jeek/Run/Jump & Vocalization \\
\hline Fornix transection $(\mathrm{N}=10)$ & $8.5 \pm 2.9^{*}$ & $17.5 \pm 2.4^{*}$ & $74.0 \pm 3.1 \dagger$ & $8.6 \pm 1.2$ \\
Sham-operation $(\mathrm{N}=10)$ & $21.5 \pm 2.5$ & $28.5 \pm 2.5$ & $50.0 \pm 3.9$ & $9.3 \pm 1.8$ \\
\hline
\end{tabular}

$* 0.01<p<0.02$ (Fornix transection vs sham-operation) $\quad \dagger p<0.001$ (Fornix transection vs sham-operation)

TABLE 2

EFFECT OF DESGLYCINAMIDE-LYSINE-VASOPRESSIN (DG-LVP) ON EXTINCTION OF A POLE-JUMP AVOIDANCE RESPONSE IN RATS WITH FORNIX TRANSECTION AND IN SHAM-OPERATED RATS AS EXPRESSED IN NUMBER OF CAR'S $( \pm$ SF,M)/SESSION

\begin{tabular}{|c|c|c|c|c|c|c|c|c|c|}
\hline \multirow{2}{*}{ Fornix Transections } & \multicolumn{6}{|c|}{ Acquisition } & \multicolumn{3}{|c|}{ Extinction } \\
\hline & & & & & & & & & \\
\hline Day & I & II & III & IV & $\mathrm{VI}$ & & VI & VII & VIII \\
\hline Placebo $(N=7)$ & 0.7 & 6.6 & 7.7 & 8.5 & 8.4 & & $5.7 \pm 1.3^{1)}$ & $3.3 \pm 1.1 \dagger$ & $2.0 \pm 0.7$ \\
\hline $3 \mu \mathrm{g}$ DG-LVP $(\mathrm{N}=6)$ & 2.3 & 3.3 & 6.7 & 7.4 & 7.7 & & $6.0 \pm 1.3$ & $5.0 \pm 1.2 \dagger$ & $4.5 \pm 0.8^{*}$ \\
\hline $9 \mu \mathrm{g} \mathrm{DG}-\mathrm{LVP}(\mathrm{N}=5)$ & 1.4 & 3.6 & 5.4 & 7.0 & 9.0 & & $8.4 \pm 1.0$ & $8.0 \pm 1.0 \dagger$ & $7.4 \pm 0.9 \ddagger$ \\
\hline \multicolumn{10}{|l|}{ Sham Transections } \\
\hline Day & I & II & III & IV & $\mathrm{V}$ & VI $\downarrow$ & VII & VIII & IX \\
\hline Placebo $(N=11)$ & 0.7 & 4.1 & 3.7 & 7.0 & 7.4 & 7.6 & $2.1 \pm 0.6$ & $1.4 \pm 0.7 \dagger$ & $0.4 \pm 0.2$ \\
\hline $3 \mu \mathrm{g}$ DG-LVP $(\mathrm{N}=9)$ & 0.1 & 3.2 & 4.5 & 6.5 & 8.0 & 7.5 & $6.2 \perp 0.7 \dagger$ & $5.0 \pm 0.7 \dagger$ & $4.7 \pm 0.9 \dagger$ \\
\hline
\end{tabular}

TABLE 3

THE EFFECT OF ACTH $4-10$ ON EXTINCTION OF A POLE JUMP AVOIDANCE RESPONSE IN RATS WITH FORNIX TRANSECTION AND IN SHAM-OPERATED RATS AS EXPRESSED IN NUMBER OF CAR'S ( \pm SEM)/SESSION

\begin{tabular}{|c|c|c|c|c|c|c|c|c|c|}
\hline \multirow{2}{*}{ Fornix Transections } & \multicolumn{6}{|c|}{ Acquisition } & \multicolumn{3}{|c|}{ Extinction } \\
\hline & & & & & & & & & \\
\hline Day & I & II & III & IV & $\mathrm{V}$ & & $\downarrow$ & VI & $\downarrow \quad$ VII \\
\hline Placebo $(N=10)$ & 0.9 & 4.1 & 6.7 & 7.4 & 8.8 & & & $6.2 \pm 1.2^{1)}$ & $4.0 \pm 1.2$ \\
\hline $3 \mu \mathrm{g} \mathrm{ACTH}_{4-10}(\mathrm{~N}=10)$ & 0.0 & 3.8 & 6.0 & 7.4 & 8.1 & & & $6.8 \pm 0.7$ & $4.5 \pm 1.4$ \\
\hline $9 \mu \mathrm{g} \mathrm{ACTH}_{4-10}(\mathrm{~N}=10)$ & 0.5 & 4.3 & 5.5 & 6.2 & 8.2 & & & $6.7 \pm 1.0$ & $4.6 \pm 1.3$ \\
\hline \multicolumn{10}{|l|}{ Sham Transections } \\
\hline Day & I & II & III & IV & $\mathrm{V}$ & VI & $\downarrow$ & VII & $\downarrow \quad$ VIII \\
\hline Placebo $(\mathrm{N}=11)$ & 1.5 & 3.0 & 4.1 & 5.3 & 6.6 & 8.4 & & $6.6 \pm 1.0$ & $3.2 \pm 0.9$ \\
\hline $3 \mu \mathrm{g} \mathrm{ACTH}_{4-10}(\mathrm{~N}=9)$ & 1.4 & 3.4 & 5.4 & 6.2 & 6.8 & 8.3 & & $8.6 \pm 0.4$ & $6.6 \pm 0.8^{*}$ \\
\hline
\end{tabular}

$\downarrow$ injection $\quad * 0.01<p<0.02^{\circ}$

extinction of conditioned avoidance behavior is completely blocked by the fornix transection. Whereas $3 \mu \mathrm{g}$ ACTH $4-10$ induced inhibition of extinction of the CAR after daily injection during extinction, this peptide was ineffective in this respect in rats with fornix transections, even in a high dose of $9 \mu \mathrm{g}$ (Table 3).

\section{DISCUSSION}

The cuts destroy connections between the limbic system and the hypothalamus (see Fig. 1). In particular the fornix-of which the pre-commissural component projects to the septum and the area preoptica and the postcommissural 
component to the corpora mammillaria $[17,19,20]-$ and the tractus corticohypothalamicus which projects to the NN. arcuatis and periventricularis $[13,17]$ are interrupted completely. Additionally the stria terminalis, originating in the amygdala, is transected. The stria terminalis runs both preand postcommissurally: the precommissural component projects to the NN. ventromedialis of the basal hypothalamus, and the postcommissural component projects to the area preoptica.

Rats normally show a decrease in exploration during subsequent sessions in an open field, indicating that a certain rate of adaptation occurs. The higher activity of the fornix transected animals as presently observed on Day 3 may therefore point to a lower degree of adaptive behavior. These open field data are consistent with the lower level of freezing responses, the increased spontaneous motor activity and decrease in time spent in total sleep others have found to follow fornicotomy $[1,14,40]$.

The observation that the difference in reactions to EFS. between rats with fornicotomy and sham-operated animals is not associated with a difference in vocalization suggests that one is dealing with a difference in motor responsiveness rather than in sensitivity to EFS. This difference in responsiveness to EFS may at least partly underly the difference in acquisition of the CAR between the rats with fornix transection and sham-operated animals since the acquired response is an avoidance of shock.

The limbic system is known to be involved in behavior which is driven by emotional conditions and several behavioral changes have been shown to follow disruption of the system, in particular by fornicotomy $[15,22]$. Although fornix lesions appeared to improve shuttle box avoidance learning [6] and rats with limbic-fornix lesions showed facilitation to the acquisition of a CAR in other situations with motivational cues [1] fornicotomy has been shown to produce deficits in the reversal of position habits [12] and to retard learning probably by producing shifts in behavioral control from motivational states to external stimuli $[5,6,11]$. Since it has been argued that ACTH peptides improve attention or affect retrieval processes by increasing the motivational value of environmental stimuli and so increase the probability that stimulus specific responses occur, the present data may be consistent with these suggestions. On the other hand it has been demonstrated that fornix lesions impaired spatial learning and the primary behavior deficit of fornicotomy may be an impairment in the ability to discriminate spatially $[5]$. Since these transections disrupt the major extrinsic connections of the hippocampus it has been suggested that in spatially organized behaviors the hippocampus plays an important role [18]. This suggestion has also been made by Black (t) al. $[2]$ saying that the hippocampus is primarily involved in information processes on places and less in behavior in which cue strategies are employed.

Complete fornix transection would transect all hippocampal efferents and eliminate direct septal input to the hippocampus. Nevertheless we have found that both the dorsal hippocampus and the septal region needed to be intact for ACTH as well as for vasopressin to inhibit the extinction of a CAR $[32,35,38]$, while we have now shown that an intact limbic system is only needed for the behavioral effects od ACTH and not for that of vasopressin. This difference may indicate that the septal region and the dorsal hippocampal complex are more or less restricted and independent anatomical substrates for the behavioral effect of vasopressin, whereas the limbic system in toto is a more functional substrate for the effect of ACTH on behavior.

Since ACTH 4-10 acts on processes involved in attention. motivation and/or retrieval $[16,21,26,30]$, the transection probably interfered with these processes. On the other hand vasopressin plays an important role in memory processes related to storage of information $[31,34,36]$ and DG-LVP could still improve the behavioral performance of animals with fornix transections. Thus the present data may indicate that disruption of the limbic system by fornicotomy interferes not necessarily with avoidance hehavior at the level of storage, but rather at the level of retrieval, attention or motivation. Therefore, it is suggested that the differential effects of fornix transection on the behavioral effects of $\mathrm{ACTH}$ and vasopressin may discriminate between the effects on processes related to attention, motivation or retrieval and those on memory consolidation.

\section{REFERENCES}

1. Alvarez-Palaez, R. Effects of fimbria-fornix lesions on avoidance conditioning in the rat. Physiol. Behav. 11: 603-607, 1973.

2. Black. A. H., L. Nadel and Y. O'Keefe. Hippocampal function in avoidance learning and punishment. Psychol. Bull. 84: 11071129,1977

3. Bohus. B. and D. de Wied. Inhibitory and facilitatory effect of two related peptides on extinction of avoidance behavior. $S_{i} ;-$ ence 153: 318-320. 1966.

4. Bohus, B. and D. de Wied. Failure of $\alpha-M S H$ to delay extinction of conditioned avoidance behavior in rats with lesions in the parafascicular nuclei of the thalamus. Physiol. Behal. 2: 221223. 1967.

5. De Castro, J. M. A selective spatial discrimination deficit after formicotomy in the rat. Rehav. Biol 12: 373-382, 1975

6. De Castro. J. M. and T. W. Hall. Fornix lesions: Effects on active and passive avoidance behavior. Physiol. Pswhol. 3 : 201-204, 1975.

7. Gispen, W. H., Tj. B. van Wimersma Greidanus and D. de Wied. Effects of hypophysectomy and ACTH $1-10$ on responsiveness to electric shock in rats. Physiol. Behav. 5: 143146. 1970.
8. Gispen, W. H., A. van der Poel and Tj. B. van Wimersma Greidanus. Pituitary-adrenal influences on behavior: responses to test situations with or without electric footshock. Physiol. Behar. 10: 345-350, 1973.

9. Halász, B. and L. Pupp. Hormone secretion of the anterior pituitary gland after physical interruption of all nervous pathways to the hypophysiotropic area. Endocrimology 77: 553-562, 1965.

10. Heimer, L. and W. J. H. Nauta. The hypothalamic distribution of the stria terminalis in the rat. Brain Res. 13: 284-297. 1969.

11. Henderson, J. and E. Greene. Behavioral effects of lesions of precommissural and postcommissural fornix. Brain Res. Bull. 2: 123-129, 1977.

12. Hirsch. R. and M. Segal. Complete transection of the fornix and reversion of position habit in the rat. Physiol. Behas. 8: 1051$1054,1972$.

13. Krieg. W. J. S. The hypothalamus of the albino rat, J. (omp) Neirol. 55: 19-89.1932.

14. Liss, Ph. Avoidance and freezing behavior following damage to the hippocampus or fornix. J. comp. physiol. Psychol. 66: 193197, 1968 . 
15. McCleary, R. A. Response-modulating functions of the limbic system: Initiation and suppression. In: Progress in Physiol. Psychol., Vol. 1, edited by E. Stellar and J. M. Sprague. New York: Academy Press, 1966, pp. 209-272.

16. Miller, L. H., A. J. Kastin and C. A. Sandman. Psychobiological actions of MSH in man. In; Frontiers of Hormone Re search, Vol. 4, edited by F. J. H. Tilders, D. F. Swaab and Tj. B. van Wimersma Greidanus. Basel: Karger, 1977, pp. 153-161.

17. Nauta, W. J. H. An experimental study of the fornix system in the rat. $J$. comp. Neurol. 104: 247-272, 1956.

18. Olton, D. S. J. A. Walker and F. H. Gage. Hippocampal connections and spatial discrimination. Brain Res. 139: 295-308, 1978.

19. Raisman, G. The connextions of the septum. Brain 89: 317-348, 1966.

20. Risman, G. and W. M. Cowan. An experimental analysis of the projection of the hippocampus. Brain 89: 83-108, 1966.

21. Rigter, H., H. van Riezen and D. de Wied. The effects of $A C T H$ - and vasopressin-analogues on $\mathrm{CO}_{2}$-induced retrograde amnesia in rats. Physiol. Behav. 13: 381-388, 1974.

22. Thomas, G. J., G. Hostetter and D. J. Basker. Behavioral functions of the limbic system. In: Progress in Physiol. Psychol.. Vol. 2, edited by E. Stellar and J. M. Sprague. New York: Academic Press, 1968, pp. 230-311.

23. Weijnen, J. A. W. M. and J. L. Slangen. Effects of ACTHanalogues on extinction of conditioned behavior. In: Pituitary, Adrenal and the Brain, edited by D. de Wied and J. A. W. M. Weijnen. Prog. Brain Res. 32: 221-235, 1970.

24. Wied, D. de. Inbibitory effect of ACTH and related peptides on extinction of conditioned avoidance behavior in rats. Proc. Soc. c.xp. Biol. 122: 28-32, 1966.

26. Wied, D. de. Pituitari-Adrenal System Hormones and Behavior. The Nerurosciences, 3rd Study Program, edited by F. $O$. Schmitt and F. G. Worden. Cambridge: M.I.T. Press, 1974, pp. 653-666.

26. Wied, D. de. Peptides and behavior. Life Sci. 20: 195-204, 1977.

27. Wied, D. de. Hormonal influences on motivation, learning and memory processes. Hosp. Pract. 11: 123-131. 1976.

28. Wied, D. de and B. Bohus. Long term and short term effect on retention of a conditioned avoidance response in rats by pretreatment respectively with long acting pitressin or $\alpha-\mathrm{MSH}$. Nature' 212: 1484-1488, 1966.

29. Wied, D. de, H. M. Greven, S. Lande and A. Witter. Dissociation of the behavioral and endocrine effects of lysine vasopressin by tryptic digestion. Br. J. Pharmac. 45: 118-122, 1972.
30. Wied, D. de, B. Bohus, W. H. Gispen, I. Urban and Tj. B. van Wimersma Greidanus. Hormonal influences on motivational, learning and memory processes. In: Hormones, Behavior and Psychopathology, edited by E. J. Sachar. New York: Raven Press, 1976, pp. 1-14.

31. Wied, D. de, Tj. B, van Wimersma Greidanus, B. Bohus, I. Urban and W. H. Gispen. Vasopressin and memory consolidation. In: Perspectives Brain Res., edited by M. A. Corner and D. F. Swaab. Prog. Brain Res. 45: 181-194, 1976.

32. Wimersma Greidanus, Tj. B. van. Effects of MSH and related peptides on avoidance behavior in rats. In: Frontiers of Hormone Research, Vol. 4, edited by F. J. H. Tilders, D. F. Swaab and Tj. B. van Wimersma Greidanus. Basel: Karger, 1977, pp. 129-139.

33. Wimersma Greidanus, Tj. B. van and D. de Wied. Effects of systemic and intracerebral administration of two opposite acting ACTH-related peptides on extinction of conditioned avoidance behavior. Nemoendocrinology 7: 291-301, 1971.

34. Wimersma Greidanus, Tj. B. van and D. de Wied. Modulation of passive avoidance behavior of rats by intracerebroventricular administration of antivasopressin serum. Behar. Biol. 18: 325333, 1976.

35. Wimersma Greidanus, Tj. B. van and D. de Wied. Dorsal hippocampus: a site of action of neuropeptides on avoidance behavior? Pharmac. Biochem. Behav. 5: Suppl 1, 29-33, 1976.

36. Wimersma Greidanus, Tj. B. van and D. de Wied. The physiology of the neurohypophysial system and its relation to memory processes. In: Biochemical Correlates of Brain Structure and Finction, edited by A. N. Davison. New York: Academic Press, 1976, pp. 215-248.

37. Wimersma Greidanus, Tj. B. van, B. Bohus and D. de Wied. Differential localization of the influence of lysine vasopressin and of ACTH 4-10 on avoidance behavior: a study in rats bearing lesions in the parafascicular nuclei. Neumendocrinology 14: 280-288, 1974

38. Wimersma Greidanus, Tj. B. van, B. Bohus and D. de Wied. CNS sites of action of ACTH, MSH and vasopressin in relation to avoidance behavior. In: Anatomicat Netroendocrinology. edited by W. F. Stumpf and L. D. Grant. Basel: S. Karger AG, 1975 , pp. 284-289.

39. Wimersma Greidanus, Tj. B. van, G. Croiset, E. Bakker and H. Bouman. Amygdaloid lesions block the effects of neuropeptides (vasopressin, ACTH 4-10) on avoidance behavior. Physiol. Behav. 22: 291-296, 1979.

40. Yamazaki, S., S. Iwahara, K. Yoshida and S. Yoshida. Effects of fornix lesions on waking and sleep patterns in white rats. Physiol. Behav. 18: 41-46, 1977. 